\title{
POSSIBILITY OF USING LICHEN AND MISTLETOE EXTRACTS AS POTENTIAL NATURAL WOOD PRESERVATIVE
}

\author{
Ümit Cafer Yildiz', Ceyhun Kiliç ${ }^{2}$, Ayşenur Gürgen ${ }^{1}$, Sibel Yildiz ${ }^{1}$
}

\begin{abstract}
Increasing environmental pressures on toxic chemical wood preservatives lead to the development of natural and environmentally friendly wood preservatives. In this study, using possibilities of lichen (Usnea filipendula) and leaves of mistletoe (Viscum album) as potential natural wood preservative were researched. Impregnation procedure was applied at four different concentration levels and with two different extraction methods (hot water and methanol). The concentration levels were arranged as 3\%, 5\%, $10 \%, 15 \%$ for hot water and as $3,75 \% ; 6,25 \% ; 12,5 \% ; 18,75 \%$ for methanol. The treatment procedure has been applied according to the ASTM D-1413 (1988) standard test method. The fungal decay test has been done according to the EN 113 (1996) standard test method using a brown rot fungus, Coniophora puteana for both treated test and untreated control samples. The best results were obtained at the highest concentration level of the solutions. However, the weight losses in treated test specimen have not met the standard requirements. Nevertheless, it can be assumed that both natural extracts provide promising protection performance.
\end{abstract}

Keywords: Decay test, retention, Usnea filipendula, Viscum album, wood protection.

\section{INTRODUCTION}

There is some concern that metal-containing wood preservatives cause environmental degradation or affect human health. A few review articles have been published about usage of natural oils and extracts in wood protection (Evans 2003, Yang 2009, Singh and Singh 2012, González-Laredo et al. 2015). From this perspective, some natural compounds that have bioactive properties can be an attractive alternative for wood protection (Singh and Singh 2012) On the other hand, González-Laredo et al. (2015) noted that "it continues to be imperative developing sustainable technologies for protecting wood and wood products from biodegradation with a minimum environmental impact. It is expected that at some point the totally organic systems will be required for wood products in residential uses". However, the performance difference between laboratory and field tests of natural preservatives has limited the commercial use of these substances (González-Laredo et al. 2015). In another aspect, it is stated that there are few limiting factors for the use of natural products in the preservation of wood, on the contrary, that there is a great potential for the evaluation of natural compounds such as wood preservatives (Singh and Singh 2012). In another review article, it is stated that natural compounds exhibit promising results, but they cannot compete with industrial wood preservatives in terms of current requirements in the wood preservation industry, low cost and long-term durability (Yang 2009).

In a preliminary study, heartwood extracts of very durable tropical hardwood species were found effective in preventing fungal attack (Onuorah 2000). In another preliminary study, Nakayama et al. (2001) noted that "the resin material extracted from the guayule plant has both insect and microbial resistance properties". The common sources of the natural compounds are extracts from bark, extracts from heartwood of durable wood species, and extracts from seed, fruit and herbaceous plants (Yang 2009). Some natural oils and food additives have been reported to be effective in preventing decay mechanism, and termite attack (Kartal et al. 2006). Poisonous extracts from oleanders were found effective against some decay fungi (Goktas et al. 2007). Alkaloids

${ }^{1}$ Department of Forestry Engineering, Karadeniz Technical University, Turkey.

${ }^{2}$ Department of non-Forest Products, Eastern Karadeniz Forestry Research Institute, General Directorate of Forestry, Trabzon, Turkey.

•Corresponding author: umitcyildiz@gmail.com

Received: 15.09.2017 Accepted: 10.12.2019 
from Sophora flavescens (Leguminosae) have proved highly effective against Formosan subterranean termites (Mao and Henderson 2007). Sen et al. (2009) conducted laboratory tests of effectiveness of some commercial extracts from fruit of valonia oak, sumac leaves, and pine bark as antifungal agents on beech and scotch pine woods. On the other hand, Abdul-Khalil et al. (2009) suggested that antioxidants in the bark of mangrove plant Rhizophora apiculata played an important role in preventing of termite attack. In a recent study, natural compounds extracted from the bark of mimosa and quebracho woods provided anti-termite potential as environmental wood protection agents for indoor applications (Tascioglu et al. 2012). In another recent study, it was also reported that the same natural extracts could protect wood against decay fungi (Tascioglu et al. 2013). Recently, some articles have been published regarding the evaluation of various natural resources as wood preservatives. It was investigated the effect of essential oils obtained from Atlas cedar wood sawdust against four decay fungi and determined that these extractive agents could prevent fungal decay (Fidah et al. 2016). In other recent study, the toxic effects of some Malaysian timbers heartwood extracts have been studied against some termite species and showed that high termite mortality was only achieved with Madhuca utilis extracts and methanol solvents (Kadir 2017). Bajraktari et al. (2018) determined the extractive content of Turkey oak (Quercus cerris) and showed that comparatively low amount of phenolics and tannins in comparison with other oaks (Bajraktari et al. 2018). The effectiveness of heartwood extracts of two Morus species against termites has been investigated and these substances have been found to be effective in preventing termite activity (Hassan et al. 2019).

It is known that lichens and mistletoe have bioactive properties. Bioactive natural products from lichens have been utilized for medicinal and cosmetic applications throughout history. The anti-microbial properties of usnic acid, one of the secondary metabolites of lichens, have been proven (Cocchietto et al. 2002). Six lichen species containing usnic acid in various quantities were found to be effective against different bacteria (Cansaran et al. 2006). On the other hand, biologically active compounds of mistletoe have been reviewed (Ochocka and Piotrowski 2002). Ertürk et al. (2004) evaluated anti-microbial effectiveness of mistletoe (Viscum album) against six bacteria and a fungus, and found that different concentration of $n$-hexane extracts of mistletoe was effective against micro-organisms tested. The objective of this research was to evaluate the possibilities of using lichen (Usnea filipendula) and mistletoe (Viscum album) extracts as natural wood preservative.

\section{MATERIAL AND METHODS}

\section{Wood materials}

Wood specimens measuring 1,5 (T) x 0,5 (R) x 2,5 (L) cm were prepared from sound sapwood of Scotch pine (Pinus sylvestris) which met requirements of ASTM D-1413 (1988). The wood specimens were conditioned at $(20 \pm 2){ }^{\circ} \mathrm{C}$ and $(65 \pm 3) \%$ relative humidity for 2 weeks.

\section{Plant material}

Lichen (Usnea filipendula) was collected from wild areas in Trabzon province Tonya district (Figure 1). Mistletoe (Viscum album) was collected from Trabzon province Sürmene district located in the north-eastern of Turkey (Figure 2). The plants were brought to laboratory for extraction.

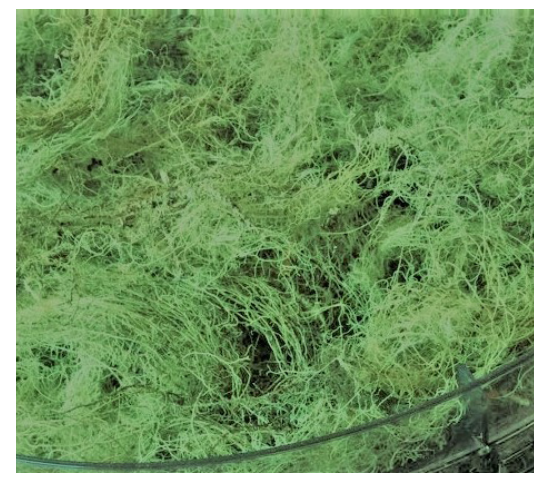

Figure 1: Lichen (Usnea filipendula). 


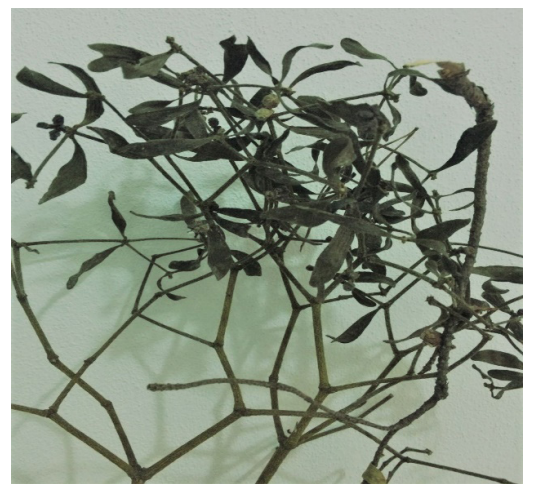

Figure 2: Mistletoe (Viscum album).

\section{Preparation of treatment solutions}

Lichen and leaves of mistletoe were dried in an oven at $60^{\circ} \mathrm{C}$ at 24 hours before grinding. A laboratory scale Wiley mill was utilized to grind the coarse particles further until they pass through a 60-mesh screen for the subsequent (1) hot water, and (2) methanol extraction process (Figure 3 and Figure 4). For hot water extraction, solutions were prepared with distilled water at 3\%, 5\%,10\%,15\% (by weight) concentration levels from all fine powders. The prepared solutions were subjected to hot water extraction on a hot plate at $80{ }^{\circ} \mathrm{C}$ for a period of 2 hours under continuous stirring with a magnetic stirrer. For methanol extraction, in order to obtain methanol solutions at 3,75\%;6,25\%;12,5\%;18,75\% concentration levels, $2,6,10$ and $14 \mathrm{~g}$ of plant powders were placed into a falcon tube. Then, methanol (99\%) was added to the tube and the mixture was stirred continuously with a shaker (Heidolph Promax 2020, Schwabach, Germany) at room temperature for a total of 2 hours. The difference in concentration between hot water solutions and methanol solutions is due to the specific gravity difference between water and methanol. However, the amount of active chemical substance (plant powder) used in each solution is the same. As the basic value that should be taken into consideration here is the amount of active chemical, it can be stated that the small differences between the solution concentrations can be neglected. All extracted solutions were filtrated by Whatman No:4 after cooling for subsequent treatments. Since the concentration values expressed herein are not the concentration of impregnation solution but the concentration of the extraction solution, the retentions thus obtained are also retentions of the extraction solution.

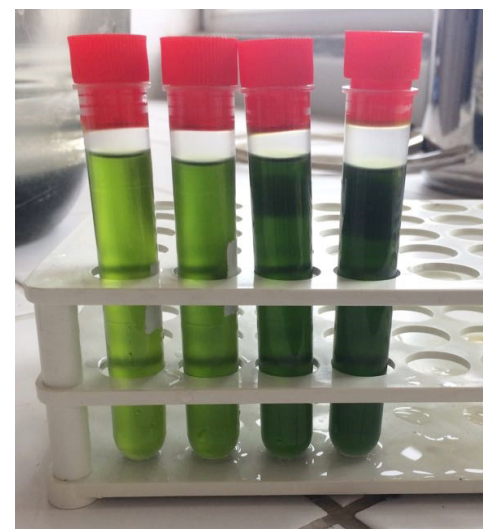

Figure 3: Treatment solutions prepared by mistletoe. 


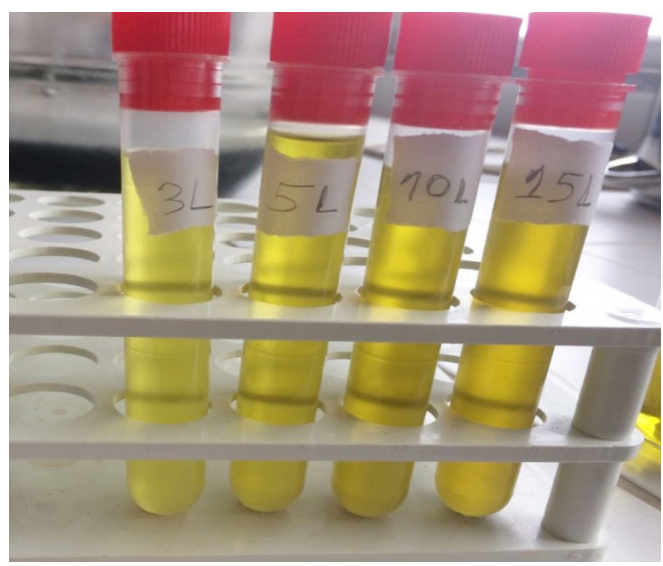

Figure 4: Treatment solutions prepared by lichen.

\section{Treatment method}

The treatment procedure was applied according to the ASTM D-1413 (1988) standard test method. The whole experiment was performed with ten repetitions. The samples were impregnated in a medium scale impregnation container using a vacuum of $635 \mathrm{~mm}$ of $\mathrm{Hg}$ for $40 \mathrm{~min}$ followed by $15 \mathrm{~min}$ atmospheric pressure. Treated samples were then removed from the treatment solution, wiped lightly to remove solution from the wood surface, and weighed to the nearest $0,01 \mathrm{~g}$ to determine the retention of each solution.

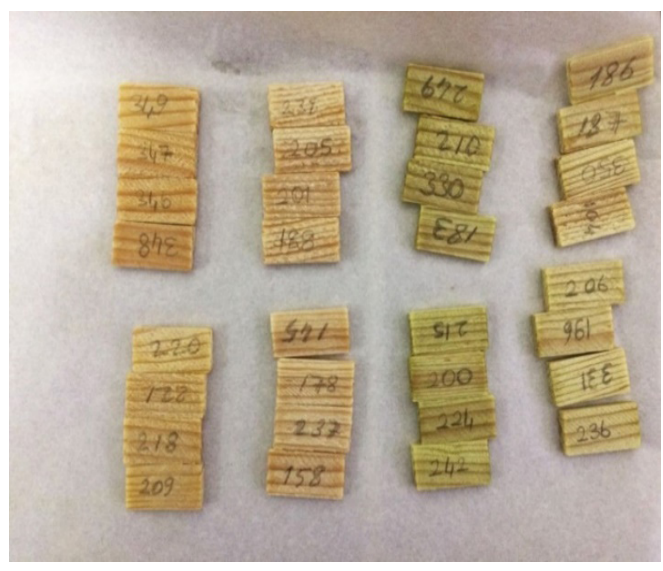

Figure 5: Treated samples.

Untreated blocks were used as controls. The retention for each concentration was calculated using the following Equation 1 and Equation 2:

$$
\begin{aligned}
& R_{1}=(G \times C / V) \times 10\left(\mathrm{~kg} / \mathrm{m}^{3}\right) \\
& R_{2}=\left(T_{2}-T_{1} / T_{1}\right) \times 100(\%)
\end{aligned}
$$


Where:

$\mathrm{R}_{1}$ : is the retention in $\mathrm{kg}$ per cubic meter

$\mathrm{R}_{2}$ : is the retention in percentage

$\mathrm{G}=\left(\mathrm{T}_{2}-\mathrm{T}_{1}\right)$ : grams of treatment solution absorbed by the wood specimen (initial weight of specimen subtracted from initial weight plus the treatment solutions absorbed),

$\mathrm{C}$ : grams of extracted solution in $100 \mathrm{~g}$ of the treatment solution

$\mathrm{V}$ : volume of specimen in cubic centimeters

$\mathrm{T}_{2}$ : sample of weight after treatment

$\mathrm{T}_{1}$ : sample of weight before treatment

The treated wood blocks were stored in a conditioning room at $(20 \pm 2){ }^{\circ} \mathrm{C}$ and $(65 \pm 3){ }^{\circ} \mathrm{C}$ relative humidity until they reach stable weight before the decay resistance tests.

\section{Decay resistance test}

The fungal decay test was done according to the EN 113 (1996) standard test method using a brown rot fungus, Coniophora puteana for both treated test and untreated control samples. Four replicates for each treatment were used. The incubation time was approximately 7 weeks at $22{ }^{\circ} \mathrm{C}$ and $70 \%$ relative humidity. After incubation, the samples were dried at temperature of $(103 \pm 2){ }^{\circ} \mathrm{C}$, weighed and the mass loss caused due to fungal attack calculated as follows (Equation 3):

$$
\operatorname{Mass} \operatorname{loss}(\%)=\left[\left(m_{o}-m_{d}\right) / m_{o}\right] \times 100
$$

\footnotetext{
Where:

$\mathrm{m}_{\mathrm{o}}$ : is the oven dry mass prior to test

$\mathrm{m}_{\mathrm{d}}$ : is the oven dry mass after the test
}

\section{RESULTS AND DISCUSSION}

\section{Retention}

$R_{1}\left(\mathrm{~kg} / \mathrm{m}^{3}\right)$ retention levels of treated Scotch pine are shown Figure 6 and Figure $7 . R_{1}\left(\mathrm{~kg} / \mathrm{m}^{3}\right)$ and $R_{2}(\%)$ retention levels are also presented in Table 1. As can be seen from Figure 6 and Figure 7, the mistletoe retentions were found higher than lichen retentions at all concentrations. Also, the retention of solutions prepared with hot water extraction were found higher than the retention of solutions prepared with methanol in both lichen and mistletoe. The retention rate of natural extract solutions was the highest in $15 \%$ mistletoe prepared with hot water, and the lowest in 3,75\% mistletoe preapered with methanol. Similiar to mistletoe, the highest retention in lichen was obtained in $15 \%$ hot water extraction solution, and the lowest in 3,75\% methanol extraction solution. As seen in Table 1, the increase in concentration had a possitive effect on retention. In contrast, this effect is much less in the percentage retention (Table 1). All the solutions gave different retention increases of between 81 and $150 \%$. In a similiar study using natural extracts, it was observed that as the solution concentration increased, the amount of retention increased (Sen et al. 2009). In addition, it has been stated that in the solutions obtained from mimosa and quebracho bark extracts, as the concentration increases from $3 \%$ to $12 \%$, the retention values are also increased (Tascioglu et al. 2013). In the present study, the retention values are the values obtained by using the entire plant body, not the active chemical substances within plant. Therefore, the higher retention values can be regarded as a normal result. 


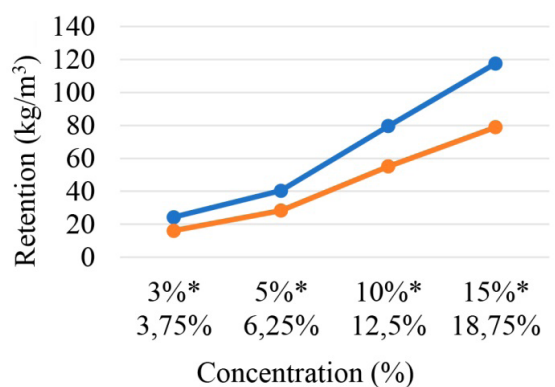

$\rightarrow$ Water solution $\rightarrow-$ Methanol solution

Figure 6: $\mathrm{R}_{1}$ retention levels of lichen.

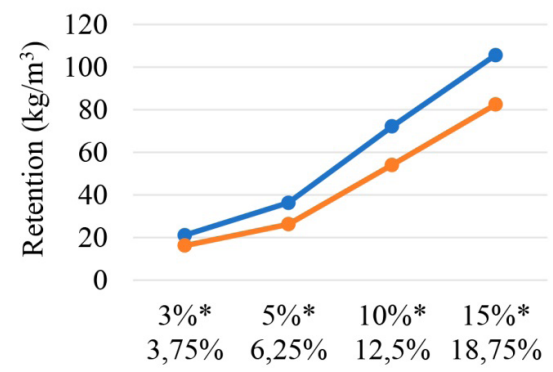

Concentration (\%)

$\rightarrow$ Water solution - Methanol solution

Figure 7: $\mathrm{R}_{1}$ retention levels of mistletoe.

In the Figure 6 and Figure 7 marked values show water solution concentrations (\%), the others show methanol solution concentrations.

Table 1: Retention levels of wood specimens treated with solutions.

\begin{tabular}{|c|c|c|c|c|c|c|}
\hline \multirow{3}{*}{ Plant } & Concentration & \multicolumn{2}{|c|}{ Retentions } & Concentration & \multicolumn{2}{|c|}{ Retentions } \\
\cline { 2 - 7 } & $\begin{array}{c}\text { Water } \\
\text { solutions (\%) }\end{array}$ & $\begin{array}{c}\mathrm{R}_{1} \\
\left(\mathrm{~kg} / \mathrm{m}^{3}\right)\end{array}$ & $\begin{array}{c}\mathrm{R}_{2} \\
(\%)\end{array}$ & $\begin{array}{c}\text { Methanol } \\
\text { solutions (\%) }\end{array}$ & $\begin{array}{c}\mathrm{R}_{1} \\
\left(\mathrm{~kg} / \mathrm{m}^{3}\right)\end{array}$ & $\begin{array}{c}\mathrm{R}_{2} \\
(\%)\end{array}$ \\
\hline \multirow{4}{*}{ Lichen } & 3 & 21,0 & 145,3 & 3,75 & 16,2 & 85,4 \\
\cline { 2 - 7 } & 5 & 36,3 & 146,1 & 6,25 & 26,2 & 83,5 \\
\cline { 2 - 8 } & 10 & 72,2 & 150,4 & 12,5 & 54,0 & 90,6 \\
\cline { 2 - 8 } & 15 & 105,6 & 140,8 & 18,5 & 82,4 & 93,1 \\
\hline \multirow{3}{*}{ Mistletoe } & 3 & 24,3 & 118,9 & 3,75 & 16,1 & 85,3 \\
\cline { 2 - 8 } & 5 & 40,4 & 126,2 & 6,25 & 28,4 & 98,5 \\
\cline { 2 - 8 } & 10 & 79,6 & 118,2 & 12,5 & 55,1 & 88,4 \\
\cline { 2 - 7 } & 15 & 117,6 & 110,6 & 18,5 & 78,9 & 81,4 \\
\hline
\end{tabular}

\section{Decay resistant}

Data of laboratory decay test using treated wood specimens and non-treated controls are shown in Figure 8 and Figure 9. The figures show that the weight losses of untreated control samples are higher than those in treated wood specimens in both lichen and mistletoe. Untreated control samples of lichen and mistletoe extracts gave mean weigt losses of $29,1 \%$ and $28,1 \%$, respectively, indicating vigorous fungal activity of $C$. 
puteana under the test conditions. Weight losses were less in specimens treated with high concentration solutions. The highest weight loss $(19,8 \%)$ was obtained in the hot water extracted $3 \%$ lichen solution, while the lowest weight loss $(6,8 \%)$ was found in the methanol extracted $18,75 \%$ lichen solution (Figure 9). In the same solution variations, the highest weight loss was $19,3 \%$ and the lowest $8 \%$ in the samples treated with mistletoe. The weight loss values were statiscially analysed with a one way ANOVA followed by Tukey test for both lichen and mistletoe, and the results were summarized in Table 2 and Table 3. According to both tables, the weight losses of the control samples were statistically higher than those of the solution treated samples. This suggests that extraction solutions are effective in preventing decay. On the other hand, the fact that the standard deviation values for weight loss are not high allow robust analysis of our set of data and reliable interpretation. In a similiar study, Kartal et al. (2006) determined that natural plant extracts such as cinnamaldehyde, cinnamic acid, cassia oil, wood tar oil and dodecanal compounds were effective against decay fungi (Kartal et al. 2006). In another study, solutions prepared from valonia oak, sumac leaves, and pine bark were reported to be significantly effective against wood decay (Sen et al. 2009). According to the Figure 4 and Figure 5, it can be considered that methanol-extracted solutions give a higher decay resistance than the water extracted ones. However, differences in weight losses were not significant between the extraction methods in lichen and mistletoe solutions (Table 2 and Table 3). On the other hand, all one way interactions were significant at the 95\% confidence level for concentrations in the decay test. Accordingly, as the concentration increases both in the lichen and in the mistletoe solutions, the weigt loss is reduced (Table 2 and Table 3). The lowest weight losses were recorded on lichen methanol extract treated wood samples at $18,75 \%$ concentration level as $6,8 \%$. Likewise, the lowest weight loss was determined to be $8 \%$ in the methanol-extracted $18,75 \%$ mistletoe solution. Similar results have been obtained in some other studies carried out with natural extracts. Taşçığlu et al. stated that "increases in solution concentrations resulted in significant reductions in mass losses for mimosa and quebracho treated wood species tested" (Tascioglu et al. 2013).

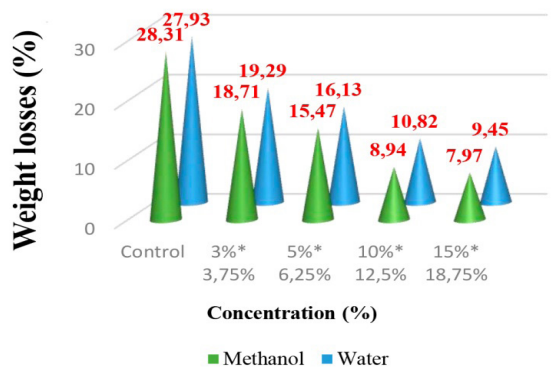

Figure 8: Weight loses of mistleote.

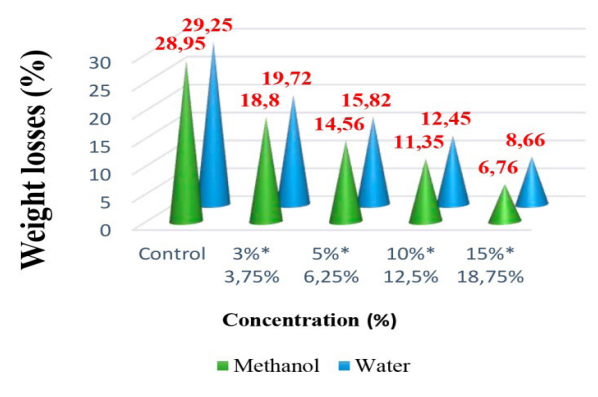

Figure 9: Weight losses of lichen.

In the Figure 6 and Figure 7 marked values show water solution concentrations (\%), the others show methanol solution concentrations. 
Table 2: Tukey test results concerned with weight losses in lichen solutions $(\alpha=0,05)$.

\begin{tabular}{|c|c|c|c|c|c|c|c|c|c|}
\hline \multirow{2}{*}{ Plant } & \multirow{2}{*}{\begin{tabular}{|c|} 
Concentration \\
$(\%)$
\end{tabular}} & \multirow{2}{*}{ Solvent } & \multicolumn{7}{|c|}{ Homogeneity groups } \\
\hline & & & 1 & 2 & 3 & 4 & 5 & 6 & 7 \\
\hline \multirow{8}{*}{ 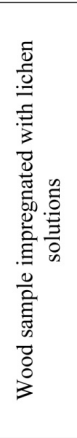 } & 18,75 & $\mathrm{M}^{\mathrm{a}}$ & $\begin{array}{c}6,8 \\
(0,43)\end{array}$ & & & & & & \\
\hline & 15 & $\mathrm{~W}^{\mathrm{b}}$ & $\begin{array}{c}8,7 \\
(0,25)\end{array}$ & $\begin{array}{c}8,7 \\
(0,25)\end{array}$ & & & & & \\
\hline & 12,5 & M & & $\begin{array}{c}11,4 \\
(1,7)\end{array}$ & $\begin{array}{l}11,4 \\
(1,7)\end{array}$ & & & & \\
\hline & 10 & $\mathrm{~W}$ & & & $\begin{array}{l}12,5 \\
(1,9) \\
\end{array}$ & $\begin{array}{l}12,5 \\
(1,9)\end{array}$ & & & \\
\hline & 6,25 & $\mathrm{M}$ & & & $\begin{array}{r}14,6 \\
(2,1)\end{array}$ & $\begin{array}{l}14,6 \\
(2,1)\end{array}$ & & & \\
\hline & 5 & $\mathrm{~W}$ & & & & $\begin{array}{l}15,8 \\
(2,6) \\
\end{array}$ & $\begin{array}{l}15,8 \\
(2,6) \\
\end{array}$ & & \\
\hline & 3,75 & $\mathrm{M}$ & & & & & $\begin{array}{l}18,8 \\
(2,7)\end{array}$ & $\begin{array}{l}18,8 \\
(2,7)\end{array}$ & \\
\hline & 3 & W & & & & & & $\begin{array}{l}19,7 \\
(2,8)\end{array}$ & \\
\hline Control & - & - & & & & & & & $\begin{array}{l}24,3 \\
(3,2)\end{array}$ \\
\hline
\end{tabular}

a: Methanol-extracted lichen solutions b: Water extracted lichen solutions.

Table 3: Tukey test results concerned with weight losses in mistletoe solutions $(\alpha=0,05)$.

\begin{tabular}{|c|c|c|c|c|c|c|}
\hline \multirow{2}{*}{ Plant } & \multirow{2}{*}{$\begin{array}{c}\text { Concentration } \\
(\%)\end{array}$} & \multirow{2}{*}{ Solvent } & \multicolumn{4}{|c|}{ Homogeneity groups } \\
\hline & & & 1 & 2 & 3 & 4 \\
\hline \multirow{8}{*}{ 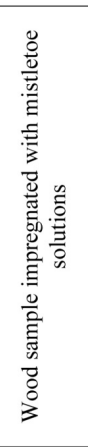 } & 18,75 & $\mathrm{M}^{\mathrm{a}}$ & $\begin{array}{c}8,0 \\
(0,9)\end{array}$ & & & \\
\hline & 15 & M & $\begin{array}{c}8,9 \\
(1,1)\end{array}$ & & & \\
\hline & 12,5 & $\mathrm{~W}^{\mathrm{b}}$ & $\begin{array}{c}9,5 \\
(1,5) \\
\end{array}$ & & & \\
\hline & 10 & W & $\begin{array}{c}10,8 \\
(1,3)\end{array}$ & & & \\
\hline & 6,25 & M & & $\begin{array}{l}15,5 \\
(1,9) \\
\end{array}$ & & \\
\hline & 5 & W & & $\begin{array}{l}16,1 \\
(1,8)\end{array}$ & $\begin{array}{l}16,1 \\
(1,8)\end{array}$ & \\
\hline & 3,75 & M & & $\begin{array}{l}18,7 \\
(1,9)\end{array}$ & $\begin{array}{l}18,7 \\
(1,9)\end{array}$ & \\
\hline & 3 & W & & & $\begin{array}{r}19,3 \\
(2,3)\end{array}$ & \\
\hline Control & - & - & & & & $\begin{array}{l}24,3 \\
(3,2) \\
\end{array}$ \\
\hline
\end{tabular}

a: Methanol-extracted lichen solutions b: Water extracted lichen solutions In the Table 2 and Table 3, the standard deviation values are given in paranthesis.

Nakayama et al. (2001) found that pine wood samples impregnated with guayule resin were higly effective against brown-rot fungi, G. trabeum, if the resin content was $52 \%$ or higher (Nakayama et al. 2001). In contrast, Göktaş et al. (2007) reported that low-concentrate solutions were more effective against white-rot fungus, $T$. versicolor than that of high concentrate in wood specimens treated with oleander extract. In our study, however, it can be stated that the extracts used had no effect such as accelerating decay in the case of increase in concentration.

The usnic acid is a natural extract produced only by lichen plant. A review summarising studies on biological activities of usnic acid in different areas has been published. In this review, it has been stated that usnic acid played many biological roles such as antibiotic, antimycotic, antifeedant, phytotoxic, photobiont regulator, UV filter, and its most important characteristic was its antibiotic activity (Cocchietto et al. 2002). Cansaran et al. (2006) found that extractive substances obtained from six different lichen species in varying proportions were higly effective against Bacillus subtilis and Bacillus megaterium. In the same study, it was also found that protective effect increased as the amount of usnic acid increased (Cansaran et al. 2006). Our results show similar findings for the antimicrobial activity of lichen extraction solutions. 
In a review article on the biologically active chemical substances of European mistletoe (Viscum album), it is stated that lectins and viscotoxins extracts are main causative agents in this sense. Continuation of this compilation, Ochocka and Piotrowski (2002) noted that "the European mistletoe is used in an adjuvant cancer therapy because of their immunostimulatory and simultaneously cytotoxic properties. These types of effects are generally more apparent for the whole extracts than for purified mistletoe lectins and viscotoxins alone" (Ochocka and Piotrowski 2002). In the current study, the mistletoe extracts were also used as a whole, and effective results were obtained. Unlike this, Ertürk et al. (2004) vaporized the mistletoe n-hexan extract and investigated its biological activity at various concentrations. Accordingly, they determined that fractions 6 and 7 of n-hexan extract of Viscum album subps. abietis had antimicrobial activity. The effective results obtained in our study can be attributed to similar active chemical agents in mistletoe extracts.

One of the most important problems in natural compounds is that they do not dissolve in water; therefore, they require organic solvent. However, the plants in our study yielded approximately similar performance in both water and methanol solutions. This should be seen as an advantage for the future.

\section{CONCLUSIONS}

In the present study, lichen and mistletoe extracts which were tested potential environmentally friendly wood preservatives. Sufficient retention values were reached in both natural extract solutions. Methanol extracts have given a somewhat higher retention value than hot water extracts. In addition, mistletoe retentions were found higher than lichen retentions at all concentrations.

Both lichen and mistletoe extraction solutions have showed good protection performance compared to the control samples. In both the lichen and the mistletoe, the lowest weight loss value has been obtained in extract solutions of $15 \%$ and $18,75 \%$ concentrations. However, the weight losses in the treated test specimen have not met the standard requirements. Nevertheless, it can be assumed that both natural extracts provide promising protection performance.

\section{ACKNOWLEDGEMENTS}

This study was financially supported by Karadeniz Technical University Scientific Research Projects Unit (FHD-2017-6018) and was declared as oral presentation in 48th IRG Annual Meeting in Belgium, 2017.

\section{REFERENCES}

Abdul-Khalil, H.; Kong, N.; Ahmad, M.; Bhat, A.; Jawaid, M.; Jumat, S. 2009. Selective solvent extraction of the bark of Rhizophora apiculata as an anti-termite agent against Coptotermes gestroi. Journal of Wood Chemistry and Technology 29(4): 286-304. https://doi.org/10.1080/02773810903165663.

ASTM. 1988. Standard Method of Testing Wood Presertives by Laboratory Soil-Block Cultures. D. 1413-76. 1988 In: Annual Book of ASTM Standards, Vol. 4.09 Wood, Philadelphia, PA, p. 239-245.

Bajraktari, A.; Nunes, L.; Knapic, S.; Pimenta, R.; Pinto, T.; Duarte, S.; Miranda I.; Pereira, H. 2018. Chemical characterization, hardness and termite resistance of Quercus cerris heartwood from Kosovo. Maderas- Cienc Tecnol 20(3): 305-314. http://dx.doi.org/10.4067/S0718-221X2018005003101.

Cansaran, D.; Kahya, D.; Yurdakulol, E.; Atakol, O. 2006. Identification and quantitation of usnic acid from the lichen Usnea species of Anatolia and antimicrobial activity. Zeitschrift für Naturforschung C 61(11-12): 773-776. https://doi.org/10.1515/znc-2006-11-1202.

Cocchietto, M.; Skert, N.; Nimis, P.; Sava, G. 2002. A review on usnic acid, an interesting natural compound. Naturwissenschaften 89(4): 137-146. https://doi.org/10.1007/s00114-002-0305-3.

Ertürk, Ö.; Kati, H.; Yayli, N.; Demirbăg, Z. 2004. Antimicrobial activity of Viscum album L. subsp. abietis (Wiesb). Turkish Journal of Biology 27(4): 255-258. 
EN 113. 1996. Wood Preservatives. Test Method for Determining the Protective Effectiveness Against Wood Destroying Basidiomycetes. Determination of the Toxic Values. Brussells, Belgium.

Evans, P. 2003. Emerging technologies in wood protection. Forest Products Journal 53(1): 14-23.

Fidah, A.; Salhi, N.; Rahouti, M.; Kabouchi, B.; Ziani, M.; Aberchane, M.; Famiri, A. 2016. Natural durability of Cedrus atlantica wood related to the bioactivity of its essential oil against wood decaying fungi. Maderas- Cienc Tecnol 18(4): 567-576. http://dx.doi.org/10.4067/S0718-221X2016005000049.

Goktas, O.; Mammadov, R.; Duru, M.E.; Ozen, E.; Colak, A.M. 2007. Application of extracts from the poisonous plant, Nerium oleander L., as a wood preservative. African Journal of Biotechnology 6(17):20002003. https://doi.org/10.5897/AJB2007.000-2307.

González-Laredo, R.F.; Rosales-Castro, M.; Rocha-Guzmán, N.E.; Gallegos-Infante, J.A.; Moreno-Jiménez, M.R.; Karchesy, J.J. 2015. Wood preservation using natural products. Madera y Bosques 21: 63-76.

Hassan, B.; Ahmed, S.; Mehmood, N.; Mankowski, M.E.; Misbah-Ul-Haq, M. 2019. Toxicity potential of heartwood extractives from two mulberry species against Heterotermes indicola. Maderas- Cienc Tecnol 21(2): 153-162. http://dx.doi.org/10.4067/S0718-221X2019005000203.

Kadir, R. 2017. Toxic effects of three selected Malaysian timbers plant extracts against subterranean termites. Maderas- Cienc Tecnol 19(4):417-432. http://dx.doi.org/10.4067/S0718-221X2017005000201.

Kartal, S.N.; Hwang, W.-J.; Imamura, Y.; Sekine, Y. 2006. Effect of essential oil compounds and plant extracts on decay and termite resistance of wood. Holz als Roh- und Werkstoff 64(6): 455-461. https://doi. org/10.1007/s00107-006-0098-8.

Mao, L.; Henderson, G. 2007. Antifeedant Activity and Acute and Residual Toxicity of Alkaloids from Sophora flavescens (Leguminosae) Against Formosan Subterranean Termites (Isoptera: Rhinotermitidae). Journal of Economic Entomology 100(3): 866-870. https://doi.org/10.1603/0022-0493(2007)100(866:aaaa ar)2.0.co;2.

Nakayama, F.; Vinyard, S.; Chow, P.; Bajwa, D.; Youngquist, J.; Muehl, J.; Krzysik, A. 2001. Guayule as a wood preservative. Industrial Crops and Products 14(2): 105-111. https://doi.org/10.1016/S09266690(00)00093-5.

Ochocka, J.R.; Piotrowski, A. 2002. Biologically active compounds from European mistletoe (Viscum album L.). Canadian Journal of Plant Pathology 24(1): 21-28. https://doi.org/10.1080/07060660109506966.

Onuorah, E.O. 2000. The wood preservative potentials of heartwood extracts of Milicia excelsa and Erythrophleum suaveolens. Bioresource Technology 75(2): 171-173. https://doi.org/10.1016/S0960-8524(99)001650 .

Sen, S.; Tascioglu, C.; Tirak, K. 2009. Fixation, leachability, and decay resistance of wood treated with some commercial extracts and wood preservative salts. International Biodeterioration \& Biodegradation 63(2): 135-141. https://doi.org/10.1016/j.ibiod.2008.07.007.

Singh, T.; Singh, A.P. 2012. A review on natural products as wood protectant. Wood Science and Technology 46(5): 851-870. https://doi.org/10.1007/s00226-011-0448-5.

Tascioglu, C.; Yalcin, M.; De Troya, T.; Sivrikaya, H. 2012. Termiticidal properties of some wood and bark extracts used as wood preservatives. BioResources 7(3): 2960-2969.

Tascioglu, C.; Yalcin, M.; Sen, S.; Akcay, C. 2013. Antifungal properties of some plant extracts used as wood preservatives. International Biodeterioration \& Biodegradation 85: 23-28. https://doi.org/10.1016/j. ibiod.2013.06.004.

Yang, D.Q. 2009. Potential utilization of plant and fungal extracts for wood protection. Forest Products Journal 59(4): 97-103. 